\title{
ACTIVIDAD DE ANTISEPTICOS EN \\ Malassezia pachydermatis AISLADA DE OIDO EXTERNO EN PERROS Y GATOS
}

\author{
(Antiseptic activity on Malassezia pachydermatis isolated from \\ external ear in dogs and cats)
}

\author{
R.G.Candido*, L.Zaror ${ }^{* *}$, O.Fischman ***, \\ Z.Gregorio*, T.Isidoro* \& J.Castanha*. \\ *Departamentode Análises Clínica, Toxicológicase Bromatológicas, \\ Fac. de Ciências Farmacéuticas de Riberao Preto, USP., Brasil \\ ** Inst. de Microbiología Clínica, Fac.,Med, Universidad \\ Austral de Chile, Valdivia, Chile. \\ *** Disciplina de Biología Celular (Micología) UNIFESP, Sao Paulo. Brasil.
}

Palabras clave: Antisépticos, Malassezia pachydermatis. oido externo, perros y gatos Key words: Antiseptics, Malassezia pachydermatis, cxternal ear,dogs and cats

\section{RESUMEN}

Se estudiaron en agar Sabouraud dextrosado, muestras obtenidas del conducto auditivo externo de 80 perros y 22 gatos aparentemente sanos. El examen micológico directo y las caracteristicas morfofisiológicas y bioquimicas, permitieron determinar la presencia de Malassezia pachydermatis en el $61,3 \%$ de las muestras provenientes de perros y en el 13,6\% de los gatos.

La susceptihilidad de esta levadura se determinó en medios sólidos, por el método de dilución in vitro fiente a soluciones de yodo, timerosal violeta de genciana. Todas las cepas fueron inhibidas en las siguientes concentraciones: Yodo $1.0 \mathrm{~g} /$ : Timerosal $0,0125 \mathrm{~g} / \mathrm{v}$ I ioleta de genciana a $0,0078 \mathrm{~g} l$, lo que representa su dilución comercial cliluida $6+1$ veces.

\section{INTRODUCCION}

Las infecciones micóticas del conducto auditivo cxterno, principalmentc del tercio posterior, se acompañan de inflamación y son producidos por hongos saprófitos y/u oportunistas. Normalmente son secundarias a una otitis bactcriana.

En general los datos sobre otomicosis son contradictorios desde su primera descripción por Mayer (1894). Algunos autores se refieren a cllas como raras y. otros como infecciones frecuentes (Maheret al. 1978).

Entre los hongos productores de otitis externas en

\section{SUMMARY}

Samples taken from the external ear duct of 80 dogs and 22 cats, which looked seemingly healthy were studied in dextrosed Sabouraud agar. The direct micological examination as well as morphophysiological and biochemical characteristics, revealed the presence of Malassezia pachydermatis in $61,3 \%$ of samples got from dogs and in 13,6\% of those from cats.

The susceptibility of this yeast was determined in solid media through the in vitro dilution method, against iodine, timerosal and gentian violet solutions. All strains were inhibited in the following concentrations: Iodine 1,9g.1; Timerosal 0,0125 g/ and Gentian violet at 0,0078 $\mathrm{g} /$, which represem their commercial dilution diluted $6+1$ times.

perros, se ha estudiado cl papel de Malassezia pachydermatis como la levadura causante de este proceso, principalmente en relación a ser o no agente primario de esta otopatía, ya que ha sido aislada de oido de perros sanos, como con otitis (Gabal etal. 1979): Gedek et al, 1979: Feigl et al.. 1981, Sanguinetti et al., 1984, Ǔchida et al. 1992. Bond et al. 1995a).

Según Gabal (1988). la asociación de M.pachydermatis con el oido canino y posiblemente de ot ras especies animales, puede ser atribuida a la presencia de cerumen. M.pachydermatis, reune todas las cepas no lipofílicas dependientes, capaces de crecer en los medios de laborato- 
rio de rutina. Se caracteriza morfológicamente por un crecimiento monopolar al producir células hijas sucesivamente a partir de un sitio en la pared celular, formando brotes prominentes (Ychida et al.,1992).

Gabal (1988), verificó que el desarrollo óptimo de esta levadura ocurre a temperatura de $37^{\circ} \mathrm{C}$ en agar Sabouraud dextrosa y en medios selectivos para dermatofitos (DTM). También el crecimiento fue estimulado en agar Sabouraud adicionado con cerumen de perro.

La aplicación de antisépticos en el tratamiento de infecciones por levaduras, se tornó secundaria con el advenimiento de los antibióticos. Sin embargo, al comprobarse la aparición de cepas resistentes a estos últimos, el uso de otros agentes como los antisépticos merecen ser reevaluados, al menos como medida complementaria o alternativa en el tratamiento, como por problemas de costo.

El objetivo de este estudio fue verificar principalmente la incidencia de M.pachydermatis en perros aparentemente sanos, así como su inhibición a diversas concentraciones de antisépticos locales.

\section{MATERIALES Y METODOS}

\section{Muestras:}

Fueron estudiadas micológicamente 80 muestras de perros y 22 gatos aparentemente sanos. de la ciudad de Riberao Preto, Brasil.

Las secresiones fueron obtenidas con tórulas embebidas en solución salina e introducidas en ambos conductos auditivos externos de los animales.

\section{Microorganismos:}

El aislamiento de hongos levaduriformesse rcalizó, sembrando las muestras en Agar Sabouraud dextrosadocloranfenicol $(100 \mathrm{mg} / \mathrm{l})$ y luego incubandolas a $37^{\circ} \mathrm{C}$ por 10 días. Para el inicio de la identificación se replicaron loscultivos en el mismo medio durante 3 dias, procediendose a la identificación por examen macroscópico y microscópico de las colonias. Además se efectuaron diferentes test bioquímicos (Tabla 1). basandonos en los esquemas de Van der Walt \& Jarrow (1984).

\section{Antisépticos:}

Se utilizaron soluciones de preparados obtenidos comercialmente como: yodoal $2 \%$, violeta de genciana al $0,5 \%$ y timerosal al $0,1 \%$.

\section{Actividad antifúngica:}

El estudio de la concentración inhibitoria mínima fue realizado en duplicado. utilizándose el test de dilución en medio sólido (Cury, !986).

Se prepararon en caldo Sabouraud. diluciones seriadas en duplicado de los antisépticos en estudio.

Las soluciones diluidas fueron incluidas en agar
Sabouraud dextrosa, previamente fundido y enfriado a 50$60^{\circ} \mathrm{C}$, para obtener concentraciones finales de yodo de 0,12 $\mathrm{g} / \mathrm{l}-2,0 \mathrm{~g} / \mathrm{l}$; timerosal $0,00625 \mathrm{~g} / \mathrm{l}-0,1 \mathrm{~g} / \mathrm{l}$ y violeta de genciana $0,00024 \mathrm{~g} / \mathrm{l}-0,0156 \mathrm{~g} / \mathrm{l}$.

En la superficie de cada placa, con el antiséptico respectivo, fueron sembradas con inoculador de Steers, las levaduras en estudio, a partir de la suspensión equivalente a $1-3 \times 10^{4} \mathrm{UFC} / \mathrm{ml}$. Las placas fueron incubadas a $37^{\circ} \mathrm{C}$. La lectura fue realizada después del crecimiento de los inóculos (48-72 hrs), en los medios controles (libres de antisépticos).

Las características morfofisiológicas y bioquímicas empleadas para la identificación de Malassezia pachydermatis, se presentan en Tabla 1.

Tabla 1. Características morfofisiológicas y bioquímicas empleadas para la identificación de Malassezia pachydermatis

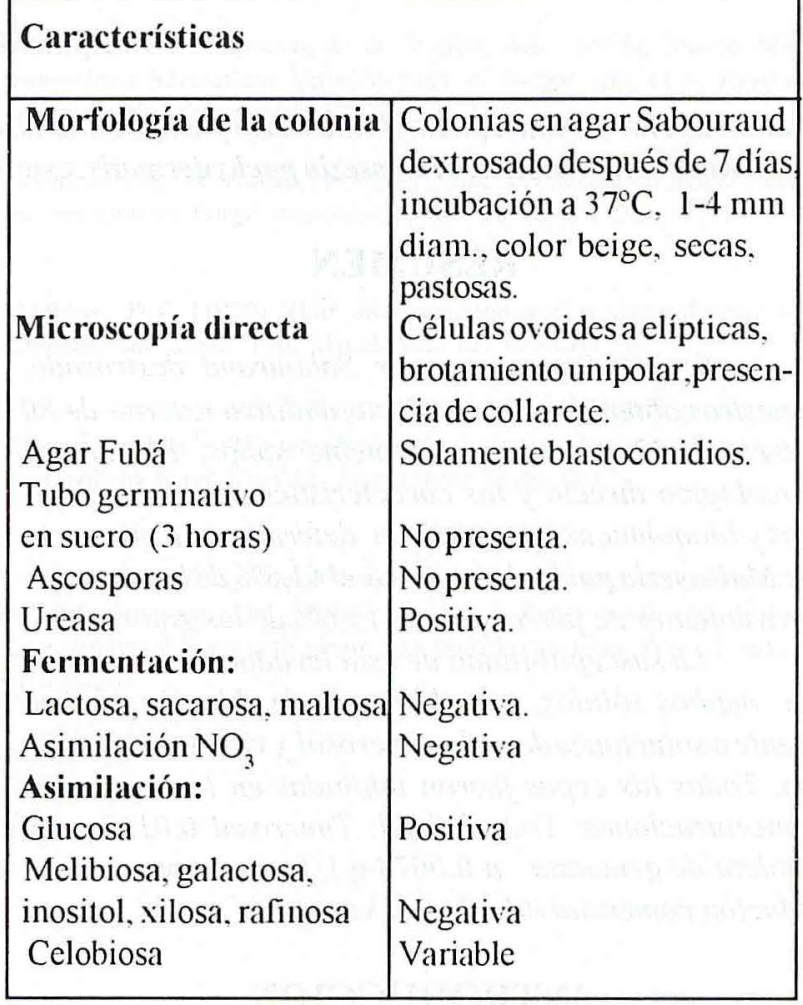

\section{RESULTADOS}

La Tabla 2, muestra que el $61,3 \%$ de los conductos auditivos de perrosalberga M.pachy'dermatis, en cambio se detectó sólo en el $13.6 \%$ de los gatos.

El cxamen microscópico directo reveló que en el $100 \%$ de los casos había células levaduriformes pequeñas, ovales, alargadas con brotes de base de implantación ancha y presencia de collarete característicos del género $\mathbf{M a -}$ 
lassezia.

Las colonias medieron entre 1-4 mm y mayoritariamente presentaron un diámetro entre $1-2 \mathrm{~mm}(73 \%)$.

En losestudios de susceptibilidad, lavioleta genciana fue el antiséptico que presentó la inhibición completa de la levadura a la dilución más baja $(0,0078 \mathrm{~g} / \mathrm{l})$ y el yodo a la más alta (1 g/l) (Tabla 3$)$.

\section{DISCUSION}

M. pachydermatis ,es una levadura no lipofilica, primariamente de interes veterinario, que ha sido referida por (Mickelsen etal., 1988), en casosesporádicosen humanos, principalmente en recién nacidos.

Somerville (1971), refiere aislamientos de esta levadura en enfermos de psoriasis severa o con micosis fungoide de la piel, mientras Romano et al., (1978), describió una canaliculitis en humanos.

En un estudio realizado en Brasil, por (Feigl et al., 1981), en 85 muestras de secreciones de oídos de perros con otitis externa y en 22 muestras de oídos de perros sanos, se verificó que M. pachydermatis y Staphylococcus aureus, fueron los agentes más frecuentemente aislados, siendo la levadura observada en el $50,8 \%$ de los caninos con otitis externa y en el $43,7 \%$ de los animales sanos.

Kuttin \& Glas (1984), observaron que en 8.750 perros, el $4,6 \%$ tenía otitis externa y en la mayoría de éstos ( $86,1 \%$ ), aislaron $\boldsymbol{M}$. pachydermatis y sólo uno presentó una otitis severa.

Observamos que los perros sanos albergan con más

Tabla 2. Aislamiento de Malassezia pachydermatis desde conductos auditivos de perros y gatos

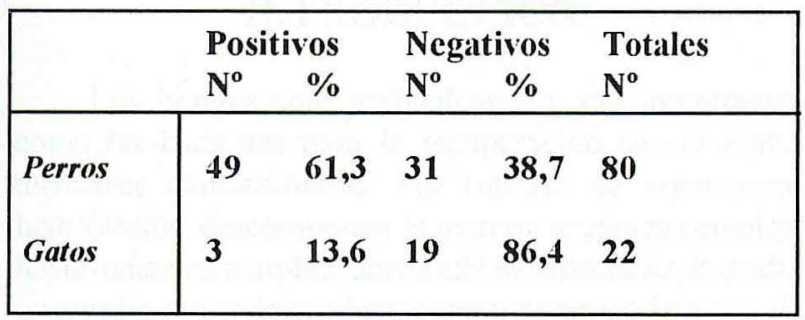

frecuencia $M$. pachydermatis en el conducto auditivo externo que los gatos. En referencia a estasituación, Sanguinetti et al. (1984), informaron del aislamiento reiterado de $M$. pachydermatis en perros y gatos y otros animales sanos o enfermos. Otros autores han comunicado del aislamiento de este hongo de oídos de perros sanos en porcentajes de $73 \%$ (Feigl et al., 1981).

Se debe tener mucho cuidadoen la incriminación de M. pachydermatis como agente de otitis canina, debido a que este microorganismo ha sido recuperado en porcentajes altos en animales sanos.
En loscasos donde se ha establecido comoagente de otitis, ha sido preconizado el uso de pimaricina (Uchida, 1992), nistatina (Feigl et al., 1984), miconazol y sulfuro de bismuto (Bond et al., 1995b).

Tabla 3. Concentración inhibitoria mínima (g/l) de antisépticos frente a 52 cepas de Malassezia .pachydermatis.

\begin{tabular}{|llll|}
\hline Antisépticos & \multicolumn{1}{c}{ Intervalo } & $\mathrm{CIM}_{50} \mathrm{a}$ & $\mathrm{CIM}_{90} \mathrm{~b}$ \\
\hline $\begin{array}{l}\text { Solución de } \\
\text { yodo } \\
\text { Solución de }\end{array}$ & $0,25-1$ & 1 & 1 \\
$\begin{array}{l}\text { timerosal } \\
\begin{array}{l}\text { Solución de } \\
\text { violeta genc. }\end{array}\end{array}$ & $0,0015-0,0125$ & 0,0031 & 0,0125 \\
\hline
\end{tabular}

$\mathrm{a}=$ Concentración que inhibió el $50 \%$ de las cepas

$\mathrm{b}=$ Concentración que inhibió el $90 \%$ de las cepas

Tratando de facilitar el tratamiento de los animales, los estudios in vitro demostraron que el $100 \%$ de las cepas analizadas fueron sensibles a concentraciones muy bajas de soluciones de timerosal, yodo y violeta de genciana.

El yodo en la concentración usual de $20 \mathrm{~g} / \mathrm{l}$ es considerado uno de los germicidas cutáneos más potentes y de menor índice de toxicidad residual (Cury,1986). En $\boldsymbol{M}$. pachydermatis, verificamos que el $100 \%$ de las muestras fueron inhibidas en la concentración de $1,0 \mathrm{~g} / \mathrm{l}$, o sea, en concentraciones 20 veces menores a las de uso habitual.

Los mercuriales orgánicos son considerados bacteriostáticos activos, con pequeña actividad bactericida.

Su uso como antiséptico es aún frecuente en nuestro medio (Cury, 1986).

El timerosal, presentó actividad inhibitoria a concentraciones iguales o menores a $0,0125 \mathrm{~g} / 1$, o sea, $1: 80$ del producto comercial.

La violeta de genciana fue el antiséptico más eficaz "in vitro" sobre las cepas de M. pachydermatis. El 100\% de ellas fueron inhibidas a concentraciones iguales 0 inferiores a $0,0078 \mathrm{~g} / 1$, lo que corresponde al producto comercial diluido 641 veces.

Concentraciones inhibitorias mínimas bajas de estos antisépticos, fueron referidas por Cury en 1986, estudiando especies de Candida. 


\section{REFERENCIAS}

Bond, R.; Saiyonmaa-Koulumieis, L.E. \& Lloyd, D.H (1995 a). Population sizes and frequency of Malassezia pachydermatis at skin and mucosal sites on healthy dogs. J. Small Anim. Pract. 36:147-150

.; Rose, J.F.; Ellis,J.W. \& LLoyd, D.H. (1995 b).Comparison of two shampoos for treatment of Malassezia pachydermatis associated seborrhoeic dermatitis in basset hounds. J.Small.Anim. Oract. 36:99-104

Cury, A.E. (1986). Actividad "in vitro" de algunos antisepticos sobre Candida. Rev.Microbiol. 17:137-142

Feigl, M.H.; Mos, E.N.; Larsson, C.E. \& Santos, M.A.A. (1981). Estudo microbiológico das otites externas em caes. Rev. Microbiol. 12: $88-91$

Gabal, M.A. (1988). Preliminary studies on the mechanism of infection on characterization of Malassezia pachydermatis in association with canine otitis externa. Mycopathologia . 104:91-98

; Chastain. C.B. \& Hogle, R.M. (1979). Pityrosporum pachydermatis ("canis") as a major cause of otitis externa in dogs. Mykosen. 22:192-199

Gedek, B.; Brutzel,K.; Gerlach,R.; Netzer, F.; Rockken;H.; Unger,H. \& Symoens, J. (1979). The role of Pityrosporum pachydermatis in otitis externa of dogs evaluation of a treatment with miconazole. Vet. Rev. 84:138-148

Kuttin, E.S. \& Glas, I. (1984). Mycotic otitis externa in animals. Mykosen. 28:61-68
Maher, Y.A.; Maher, A.\& Moawad, M.K. (1978). Otomycosis. A survey in the Eastern providence of Saudi Arabia. Scand J. Laryngol 92:869-876

Michelsen, P.A.; Viano-Paulson, M.C.; Stevens, D.A. \& Diaz, P.S. (1988).Clinical and microbiological features of infection with Malassezia pachydermatis in high-risk infants. J. Infect. Dis. 157: 1163-1168

Romano, A.; Segal, E. \& Blumenthal,M. (1978). Canaculitis with isolation of Pityrosporum pachydermatis. Br. J. Ophthalmology. 62: $732-734$

Sanguinetti, V.; Tampieri, M.P. \& Morganti, L. (1984). A survey of 120 isolates of Malassezia (Pityrosporum) pachydermatis. Mycopathologia 85:93-95

Somerville, D.A. (1971). Colonization by Pityrosporum pachydermitis. Lancet. 17:799

Uchida, Y.; Mizutani, M.; Kubo, T.; Nakade, T. \& Otomo, K. (1992). Otitis externa induced with Malassezia pachydermatis in dogs and the efficacy of pimaracin. J. Vet. Med. Sci. 54:611-614

Van der Walt, J.P. \& Yarrow, D. (1984). Methods for isolation, maintennance, classification and identification of yeasts. In : Kreger van Rij, N.J.W., ed. The yeasts: a taxonomic study. Amsterdan, Elsevier, 45-104 pp. 